\title{
Case-control study: Productivity and longevity of dairy cows that tested positive for infection with Mycobacterium avium ssp. paratuberculosis as heifers compared to age-matched controls
}

\author{
R. B. Pillars, ${ }^{\star 1}$ M. W. Bolton, $†$ and D. L. Grooms \\ ${ }^{*}$ Caine Veterinary Teaching Center, University of Idaho, Caldwell 83607 \\ tIntervet/Schering-Plough Animal Health, Technical Services-Dairy, Belding, MI 48809 \\ ¥Department of Large Animal Clinical Sciences, College of Veterinary Medicine, Michigan State University, East Lansing 48824
}

\begin{abstract}
A case-control study was performed to determine if dairy heifers testing positive for Mycobacterium avium ssp. paratuberculosis (MAP) before $2 \mathrm{yr}$ of age by either fecal culture or serum ELISA had decreased productivity and longevity as cows compared with age-matched herdmates. Cases were individually matched with 4 controls. Survival analysis was conducted to determine differences in longevity between cases and controls. Conditional logistic regression was used to assess differences in mean 3.5\% fat-corrected 305-d matureequivalent milk, milk fat, and milk protein production, linear somatic cell count, and MAP test and clinical status as mature cows. No significant difference was found between cases and controls for any parameter assessed. Herd production performance and longevity did not appear to be impaired; therefore, testing immature dairy heifers for MAP is not economically justifiable, using currently available culture methods and commercial serum ELISA tests.
\end{abstract}

Key words: dairy cow, Mycobacterium avium ssp. paratuberculosis, case-control study, Johne's disease

\section{INTRODUCTION}

Mycobacterium avium ssp. paratuberculosis (MAP) causes chronic granulomatous enteritis, primarily of ruminants, more commonly known to producers as Johne's disease (JD). It is estimated that over $68 \%$ of US dairy herds have cattle infected with MAP (USDA, 2008). Because MAP infection is untreatable in production livestock (St. Jean, 1996), control of JD is dependent on minimizing the transmission of MAP to uninfected cattle.

Studies have demonstrated that susceptibility to MAP infection is both age and dose dependent, with

Received July 29, 2010.

Accepted February 23, 2011.

${ }^{1}$ Corresponding author: rpillars@uidaho.edu young calves being the most vulnerable (Larsen et al., 1975), although cows can become infected if repeatedly exposed to high doses of MAP (Rankin, 1962; Sweeney, 1996). The paradigm over the years has been that calves become infected by ingesting MAP shed by cows, the animals most likely to be shedding the bacterium (Whitlock and Buergelt, 1996). Recent studies, however, have documented fecal shedding of MAP in naturally infected calves as young as $8 \mathrm{mo}$ of age (Antognoli et al., 2007), and horizontal transmission of MAP from calf to calf (van Roermund et al., 2007). Following an incubation period of 2 to $10 \mathrm{yr}$, infected cattle develop clinical signs of JD, including diarrhea, weight loss, and decreased productivity (Whitlock and Buergelt, 1996; Collins, 2003).

Early identification and culling of MAP-infected cattle would aid in minimizing disease transmission by limiting environmental contamination, especially if cattle are removed before the heavy shedding phase (McDonald et al., 1999; Antognoli et al., 2007). It would also eliminate the costs incurred by producers of raising infected cattle that are at high risk of developing clinical disease later in life (Antognoli et al., 2007). However, due to the slow progression of the disease, young infected calves rarely shed detectable levels of MAP using currently available culture systems, and the humoral response often does not develop until after the onset of shedding (Chiodini, 1996; Whitlock and Buergelt, 1996). Thus, early identification of infected cattle continues to be problematic.

In addition to the challenge of accurate early identification of MAP-infected cattle, economic issues must be considered. The benefit of decreasing transmission by removing test-positive cows must outweigh testing costs, production losses, decreased cull value, and opportunity costs of herd replacements (Lombard et al., 2005). The mean cost of individual fecal culture (FC) is $\$ 19 /$ sample and $\$ 5 /$ sample for serum ELISA (Collins et al., 2006). Given the high probability of false negative tests in young heifers, this testing may be difficult to justify. Moreover, if test-positive calves are slaughtered, 
they will weigh less than mature cows, resulting in a lower cull value; and they will likely need to be replaced to maintain herd size, thereby increasing replacement costs.

The effect of MAP infection on productivity and herd longevity is less clear. Decreased productivity and longevity have been well documented in cattle with clinical JD (Benedictus et al., 1987; Körmendy et al., 1989; Beaudeau et al., 2007; Raizman et al., 2007). However, in young cattle, the infection is generally subclinical, and the effect on production in subclinically infected cows less distinct. Many studies report subclinically infected cows produce less milk than their uninfected herdmates (Benedictus et al., 1987; Spangler et al., 1992; Wilson et al., 1993; Nordlund et al., 1996; Raizman et al., 2007), whereas some report no production differences (Johnson et al., 2001) or increased production (McNab et al., 1991), particularly in first-lactation cows (Wilson et al., 1993). The reason for the disparity across studies is most likely due to differences in diagnostic tests and methods used to identify MAP-infected cows and the populations studied. A consensus of a parity effect seems to exist, in that production losses increase with parity (Wilson et al., 1993; Johnson et al., 2001). Also, the more positive (higher shedding level or higher ELISA reading) a cow is, the greater the negative effect on production (Lombard et al., 2005; Raizman et al., 2007; Smith et al., 2009), and the magnitude of lost production is greater in FC-positive cows than in ELISA-positive cows (Gonda et al., 2007).

Four studies have documented fecal shedding of MAP in naturally infected calves less than 24 mo of age (Antognoli et al., 2007; van Roermund et al., 2007; Bolton, 2009; Mitchell et al., 2009) but none have followed those calves into adulthood to see how they perform as cows. Knowing the outcome of these calves could help justify the application of diagnostic assays and strategies for early detection of MAP-infected heifers. The objective of this study was to compare longevity, production performance, and adult JD test status of cows testing positive for JD as calves $(<24$ mo of age) to age-matched herdmates. Our hypothesis was heifers that tested positive for MAP were not different in terms of herd longevity, production performance, and adult MAP test status when compared with agematched controls.

\section{MATERIALS AND METHODS}

This was an individually matched case-control study. This project and the procedures described were approved by the Michigan State University Institutional Animal Care and Use Committee.

\section{Study Population}

The study population was made up of cattle from 4 commercial Holstein dairy herds enrolled in the Michigan Johne's Disease Control Demonstration Project (MJDCDP). Herds in the MJDCDP were chosen based on a known diagnosis of JD, being representative of the Michigan dairy industry in terms of herd size and housing management, and a willingness to participate. Beginning in 2004 and continuing through 2008, all cows 2 yr and older in participating herds were annually tested for MAP using serum ELISA (Parachek; Prionics AG, Schlieren-Zurich, Switzerland; positive test cutoff o.d. $\geq$ mean of negative controls +0.1 ) and FC (ESP II, ESP Culture System II; Trek Diagnostic Systems, Cleveland, $\mathrm{OH}$ ). Herds were selected for this particular study because they also participated in DHIA testing, which allowed access to production data.

\section{Cases}

Cases were defined as any cow that tested positive for Johne's disease by either serum ELISA or FC as a heifer, as identified in a previous study investigating the shedding of MAP in naturally exposed dairy calves (Bolton, 2009). Briefly, 10 heifer calves from each of 4 age groups: 0 to $3 \mathrm{mo}, 4$ to $6 \mathrm{mo}, 7$ to $14 \mathrm{mo}$, and 15 to 24 mo were selected from each herd every 4 mo and tested for MAP using a commercially available serum ELISA (Parachek; Prionics AG) and FC (ESP II, ESP Culture System II, Trek Diagnostic Systems). Calves from dams testing positive for MAP by either serum ELISA or FC were preferentially sampled with the remainder of the age cohort filled with randomly selected calves. Sampling began in April 2004 and continued through August 2006.

\section{Controls}

Each case was individually matched with 4 controls. The controls were the 4 heifer calves born immediately before or after the case on each respective herd that tested negative as heifers and survived to give birth to at least 1 calf in the herd being studied. This ensured that the cases and controls were similar in age, exposure, and management.

\section{Data Collected}

Data collected for this study were from April 2004 through August 2009 and included for both cases and controls: herd identification, date of birth, JD test status, dam's JD test status, lactation [milk, fat, and 
protein, and linear somatic cell count (LSCC)] production data, cull date, and if the cow was culled due to clinical JD when available. The $3.5 \%$ FCM, using the 305-d mature-equivalent, was calculated for each lactation using the following equation: $3.5 \% \mathrm{FCM}=(0.4323$ $\times$ pounds of milk $)+(16.216 \times$ pounds of fat $)$ (Hutjens, 2005). The mean 3.5\% FCM, fat, protein, and LSCC was calculated over the lifetime of each cow. The days spent in the herd were calculated as follows: for cows that were culled, the cow's cull date minus her date of birth; for cows remaining in the herd as of the herd's August 2009 DHI test date, the test date minus her date of birth.

\section{Data Analysis}

Data were maintained in, and descriptive statistics generated, using a commercially available spreadsheet (Microsoft Office Excel; Microsoft Corporation, Redmond, WA). Survival analysis was used to determine if a difference in time spent in the herd between cases and controls existed by calculating the Kaplan-Meier estimators (PROC LIFETEST, SAS version 9.1; SAS Institute, Inc., Cary, NC). Conditional logistic regression (PROC LOGISTIC, SAS version 9.1, SAS Institute, Inc.) was used to assess differences in mean production (3.5\% FCM, fat, protein, LSCC), JD test status as adults, removal from herd during the observation period, and JD test status of dam between cases and controls. For all analyses, a $P$-value of $<0.05$ was considered statistically significant.

\section{RESULTS}

Twenty-five cases were identified from the 4 study herds in the previous study (Bolton, 2009). Each case was matched to 4 controls, resulting in a total of 100 control cattle, and a total study population of 125 cows. Of the cases testing positive for JD before $2 \mathrm{yr}$ of age in the previous study, $16(64 \%)$ were from JD test-positive dams. The cumulative MAP test results before $2 \mathrm{yr}$ of age for the cases were $11 \mathrm{FC}$ positive, 17 ELISA positive, and 2 cases positive on both $\mathrm{FC}$ and ELISA. Six cases were JD test positive at 2 different sample collections: 4 were FC positive twice; 1 FC positive on one test date and ELISA positive on the other; and 1 was FC and ELISA positive on one test date and ELISA positive only on the following test date. The ages at which cases tested positive for both FC and serum ELISA as calves are summarized in Table 1. The majority of cases positive on FC were $\geq 7$ mo old, whereas the majority of ELISA-positive cases were $\leq 6$ mo of age. All 25 cases survived to calve as adults. Five out of $22(23 \%)$ cases tested positive for MAP as adults; all 5 were FC positive, whereas 2 were also ELISA positive. Three cases were culled from the herds without being tested as adults. A total of 11 (44\%) cases were culled from the herds by the end of the observation period, with only 1 case being culled with clinical signs consistent with JD.

Of the 100 controls 37 were from MAP test-positive dams. As adults, 18 controls were FC positive, 7 were ELISA positive, with 4 cows testing positive on both FC and ELISA. Six controls were culled from the herds without being tested as adults. Thirty-nine controls were culled from the herds by the end of the observation period, of which 2 were culled with clinical signs of JD. The median age difference between each case and its controls was $7 \mathrm{~d}$, with a range of 0 to $55 \mathrm{~d}$.

Using survival analysis, the mean number of days in the herd for cases was 1,591 (95\% CI: 1,422- 1,761), whereas that for controls was 1,721 (95\% CI: 1,635$1,807)$; however, this difference was not statistically significant $(P=0.42)$.

Conditional logistic regression revealed no statistically significant difference between cases and controls in terms of mean days spent in herd, $3.5 \%$ FCM, fat, or protein produced; LSCC; JD test status as adults;

Table 1. Age at which cases $(\mathrm{n}=25)$ tested positive for Mycobacterium avium ssp. paratuberculosis as calves

\begin{tabular}{|c|c|c|c|c|}
\hline \multirow{2}{*}{$\begin{array}{l}\text { Age } \\
\text { group }\end{array}$} & \multicolumn{3}{|c|}{ Fecal culture positive ${ }^{1}$ shedding level } & \multirow{2}{*}{$\begin{array}{c}\text { ELISA } \\
\text { positive }^{5}\end{array}$} \\
\hline & Low $^{2}$ & Moderate $^{3}$ & $\operatorname{High}^{4}$ & \\
\hline 0 to $3 \mathrm{mo}$ & 1 & 0 & 0 & 9 \\
\hline 4 to $6 \mathrm{mo}$ & 1 & 0 & 1 & 3 \\
\hline 7 to $14 \mathrm{mo}$ & 3 & 1 & 1 & 1 \\
\hline 15 to $24 \mathrm{mo}$ & 7 & 0 & 0 & 4 \\
\hline Total & 12 & 1 & 2 & 17 \\
\hline
\end{tabular}


Table 2. Results of conditional logistic regression comparing cases to controls

\begin{tabular}{lcc}
\hline Effect & $\begin{array}{c}\text { Odds ratio } \\
(95 \% \mathrm{CI})\end{array}$ & $\begin{array}{c}\text { Wald } \chi^{2} \\
P \text {-value }\end{array}$ \\
\hline Mean days spent in herd & $0.999(0.997-1.000)$ & 0.1248 \\
Mean fat-corrected 305ME milk ${ }^{1}$ & $1.000(1.000-1.000)$ & 0.9460 \\
Mean fat & $1.000(0.999-1.001)$ & 0.8796 \\
Mean protein & $1.000(0.998-1.002)$ & 0.7983 \\
Mean LSCC ${ }^{2}$ & $1.089(0.778-1.525)$ & 0.6177 \\
Fecal culture positive as mature cow & $1.230(0.376-4.018)$ & 0.7319 \\
Serum ELISA positive as mature cow & $1.163(0.217-6.227)$ & 0.8598 \\
Culled during observation period & $1.268(0.490-3.284)$ & 0.6243 \\
Dam JD ${ }^{3}$ test positive & $3.623(1.325-9.901)$ & 0.0122 \\
${ }^{1}$ 305ME $=305-d$ mature-equivalent. & & \\
${ }^{2}$ Linear SCC. & & \\
${ }^{3}$ Johne's disease. & &
\end{tabular}

or being culled during the observation period (Table 2 ). The only statistically significant difference found was that cases were 3.6 times $(95 \% \mathrm{CI}: 1.3-9.9 ; P=$ 0.012 ) more likely to have a MAP test-positive dam than controls.

Analyzing cases that were FC positive separately from cases that were ELISA positive as calves did not change the interpretation for any parameters evaluated.

\section{DISCUSSION}

In this study, no significant difference was observed in longevity, production performance, and mature cow JD test status between cases and controls. This was an unexpected outcome. Assuming the cases were truly infected with MAP, the pathogenesis of the disease would impair absorption of nutrients from the gut, which should, in turn, result in poorer production and shorter herd life compared with uninfected herdmates. Given this assumption, the most likely explanation for the finding reported here is the potential misclassification of cases and controls.

Testing individual cows for MAP, using FC or serum ELISA, is not particularly sensitive $(60 \pm 5 \%$ and 30 $\pm 5 \%$, respectively), especially when tested cattle are not exhibiting clinical signs of the disease. Meanwhile, specificity of both tests is estimated to exceed $99 \%$ (Collins et al., 2006). However, in very young animals, the specificity of both FC and the serum ELISA has been questioned (McDonald et al., 1999; Antognoli et al., 2007). It is generally accepted that as a MAPinfected animal matures, the disease progresses, making it easier to detect with currently available diagnostic tests (Collins, 2003).

Several opportunities for misclassification to occur were present in this study. It is possible the observation period was not long enough for the infection to be detected in either cases or controls as adults. Also, due to poor test sensitivity, infected calves could have tested negative and been included in the study as controls. Cases could also have been misclassified as infected with MAP as calves, which is supported by the relatively low proportion $(23 \%)$ of cases that subsequently tested positive for MAP as adults.

Of the cases that were ELISA positive, 12/16 (75\%) tested positive at less than 6 mo of age. In these cases, the test may have been detecting maternal antibodies. Maternally derived antibodies to other bovine pathogens can last as long as $200 \mathrm{~d}$ in calves (MenanteauHorta et al., 1985; Fulton et al., 2004). Presuming maternally derived antibodies to MAP follow a similar rate of decrease, coupled with the fact many of the cases had ELISA-positive dams, makes it possible that the MAP antibodies detected in the youngest calves were of maternal origin and not the result of a true infection. Further supporting this theory is the fact that the primary immune response to MAP immediately following infection is cell mediated, not humoral (Chiodini, 1996). Given that MAP is a chronic infection, with an extended incubation period of 2 to $10 \mathrm{yr}$ (Sweeney, 1996; Whitlock and Buergelt, 1996; Collins, 2003), it is unlikely that infected calves would be seropositive due to active immunity at less than 6 mo of age.

Fecal shedding of MAP in young calves $(<24$ mo of age) has been documented following both experimental (McDonald et al., 1999; Waters et al., 2003; Stabel et al., 2009) and natural exposure (McDonald et al., 1999; Antognoli et al., 2007; van Roermund et al., 2007; Bolton, 2009). Actual infection in some of these studies was confirmed by tissue culture or histopathology (McDonald et al., 1999; Waters et al., 2003; Stabel et al., 2009). However, neither was performed in the study from which our cases originated or in the current study; therefore, we cannot say with absolute certainty that the cases in this study were truly infected. Possibilities for a positive fecal culture include transient pass- 
through of MAP in an uninfected animal (Sweeney et al., 1992a), a true infection that was then cleared (Chiodini, 1996), a true infection that was not cleared and became chronic, or laboratory error.

Pass-through shedding has been documented when exposure to high levels of MAP, whether experimentally or naturally through a contaminated environment, results in the bacteria being ingested transiting the gastrointestinal tract and being eliminated in the feces, where it can then be cultured even though the animal may not be actively infected (Sweeney et al., 1992a; Stabel et al., 2009). It is certainly possible that some of the cases in this study were the result of pass-through MAP. All but 2 of the cases originated from herds with a relatively high within-herd JD prevalence (10-42\% based on annual fecal culture of all adult cattle), thereby increasing the risk of exposure to high levels of MAP. Moreover, calves from which pass-through MAP has been identified have subsequently been found to be truly infected based on tissue culture and histopathology (Stabel et al., 2009). Regardless, even if the positive fecal cultures were the result of pass-through MAP, the fact that the bacterium was identified in the feces provides evidence that the cases were exposed and, therefore, at extremely high risk of becoming infected.

Most of the cases identified by FC were first positive at $>7 \mathrm{mo}$ of age. This is a similar observation to that of another study that found a peak in the shedding of MAP in infected calves at 7 to 9 mo of age, followed by a period of no shedding before shedding was once again detected at 12 to 30 mo of age (van Roermund et al., 2007).

Multiple positive tests on different sampling dates increase the likelihood that those cases were truly infected. Bolton (2009) identified 6 such calves. Interestingly, only 1 of those calves subsequently tested positive for MAP (on both ELISA and FC) as an adult and was culled because of clinical signs. Two cases were culled from their respective herds for reasons other than JD before being tested as mature cows. Two others tested negative for MAP as adults and were culled for reasons other than JD. The remaining calf is an interesting case. She was 1 of a set of twin heifers from a MAP test-negative dam, and her twin was selected as one of her controls. She was identified as a high MAP shedder at 4 to $6 \mathrm{mo}$ of age and a low shedder at 7 to $14 \mathrm{mo}$. This alone would have suggested she was truly infected, as most pass-through shedders are not culture positive on 2 consecutive tests and most are classified as low shedders (Sweeney et al., 1992a; Whitlock et al., 2006). Meanwhile, her twin tested negative for MAP twice as a calf and both have consistently tested negative as cows and were currently in their respective third lactations as of the end this study.
The 3 cows ( 1 case, 2 controls) culled for clinical JD in this study were all from the same herd. This herd had the highest within-herd MAP test prevalence of all of the study herds, peaking at $42 \%$ during the course of this study. It is likely this herd was overly sensitized to JD. The producer admitted to coding cows as culled due to clinical JD if they had diarrhea and were a little thin, regardless of their MAP test status. The case was likely truly infected with MAP. She was FC positive twice as a heifer and was ELISA and FC positive multiple times as an adult before being culled during her third lactation. Of the other 2 cows that were culled due to JD, 1 was not tested and culled at 192 DIM, making it difficult to infer her MAP infection status. The remaining cow was MAP test negative and culled at 29 DIM. It is not uncommon for cows to lose weight and develop diarrhea early in lactation due to diet changes and increased metabolic demands during the transition period, although it is also true that stressful events such as parturition triggers MAP shedding and exacerbation of the disease (Harris and Barletta, 2001).

In this study, cases were 3.6 times more likely to have a MAP test-positive dam than controls. The magnitude and significance of this measure is likely an artifact of selection bias in the previous study from which the cases for this study were identified. In the previous study (Bolton, 2009), the primary objective was to determine if fecal shedding of MAP occurred and could be detected in naturally exposed dairy calves. It was assumed a priori that MAP shedding in calves would be a rare occurrence, but more likely to occur in calves from test-positive dams, so these calves were selectively chosen for testing. The literature supports calves from infected dams being at higher risk of becoming infected with MAP through in-utero transmission (Sweeney et al., 1992b), ingesting MAP from contaminated colostrum and milk (Sweeney et al., 1992c; Streeter et al., 1995), or fecal ingestion (Sweeney, 1996; Harris and Barletta, 2001). Aly and Thurmond (2005) reported cows from MAP seropositive dams were 6.6 times more likely to be seropositive than cows from seronegative dams. So, although a strong association between the JD test status of a cow and her dam's JD test status appears to exist, the odds ratio reported here should be interpreted with extreme caution.

The average parity for cases in this study was 2.2, whereas that for controls was 2.3. This relatively young age may explain why no significant differences in production parameters were noted between cases and controls. It is in agreement with findings previously published where the authors theorized that in herds with an average parity of 2, many cows subclinically infected with MAP would be culled before experiencing a decrease in milk production (Johnson et al., 2001). 
The average age of US Holsteins has been trending downward over the past 40 yr. During the 20 -yr period from 1966 to 1986, the average Holstein parity was 3.4 (Nieuwhof et al., 1989), whereas from 1995 to 1997, it was 2.8 (Tsuruta et al., 2005). In 2000, the average age of cows on Midwest dairy farms enrolled in DHIA with milk production levels similar to the herds in this study was 43 mo (Smith et al., 2002), which, assuming a 24-mo age at first calving and 13-mo calving interval, would suggest the average parity is now $<2$. A significant difference in production may have been found had we followed the cows in this study longer, thus allowing the disease to progress further in infected cows and increasing the probability of impaired production. However, the average age of the cows in this study was 49 mo, which is longer than the current average age across all cows in the study herds, which ranged from 41 to 45 mo.

This study may have been underpowered, which could explain why no statistically significant differences other than dam status were noted between cases and controls. Unfortunately, the number of cases in this study was dictated by the number of heifers testing positive for MAP before $2 \mathrm{yr}$ of age in a previous study. This was a relatively rare event, and further testing of young dairy replacements was beyond the scope and budgetary constraints of the previous and current studies.

In conclusion, no significant difference was observed in herd longevity, production performance, and adult MAP test status between cows testing positive for MAP before 2 yr of age (by either FC or serum ELISA) and their herdmates. Based on these results, it appears that the MAP test status of young dairy replacements, using currently available FC and serum ELISA tests, is not a reliable indicator of true infection status or future impaired production over the course of the current average lifetime of Holstein dairy cattle. Thus, testing young dairy replacements, using currently available FC and serum ELISA tests, is not justifiable from a purely economic point of view. However, from a disease control standpoint, early identification and removal of MAP-infected animals is prudent and further research is warranted.

\section{ACKNOWLEDGMENTS}

Support for this study was provided by a grant from the USDA/APHIS/VS-Johne's Disease Program. We also thank the participating dairy producers for their willingness to work with us.

\section{REFERENCES}

Aly, S. S., and M. C. Thurmond. 2005. Evaluation of Mycobacterium avium subsp paratuberculosis infection of dairy cows attributable to infection status of the dam. J. Am. Vet. Med. Assoc. 227:450454.

Antognoli, M. C., H. L. Hirst, F. B. Garry, and M. D. Salman. 2007. Immune response to and faecal shedding of Mycobacterium avium ssp. paratuberculosis in young dairy calves, and the association between test results in the calves and the infection status of their dams. Zoonoses Public Health 54:152-159.

Beaudeau, F., M. Belliard, A. Joly, and H. Seegers. 2007. Reduction in milk yield associated with Mycobacterium avium subspecies paratuberculosis (MAP) infection in dairy cows. Vet. Res. 38:625-634.

Benedictus, G., A. A. Dijkhuizen, and J. Stelwagen. 1987. Economic losses due to paratuberculosis in dairy cattle. Vet. Rec. 121:142146.

Bolton, M. W. 2009. Shedding of Mycobacterium avium ssp. paratuberculosis in naturally exposed dairy calves and associated risk factors. MS Thesis. Michigan State Univ., East Lansing.

Chiodini, R. J. 1996. Immunology: Resistance to paratuberculosis. Vet. Clin. North Am. Food Anim. Pract. 12:457-467.

Collins, M. T. 2003. Paratuberculosis: Review of present knowledge. Acta Vet. Scand. 44:217-221.

Collins, M. T., I. A. Gardner, F. B. Garry, A. J. Roussel, and S. J. Wells. 2006. Consensus recommendations on diagnostic testing for the detection of paratuberculosis in cattle in the United States. J. Am. Vet. Med. Assoc. 229:1912-1919.

Fulton, R. W., R. E. Briggs, M. E. Payton, A. W. Confer, J. T. Saliki, J. F. Ridpath, L. J. Burge, and G. C. Duff. 2004. Maternally derived humoral immunity to bovine viral diarrhea virus (BVDV) 1a, BVDV1b, BVDV2, bovine herpesvirus-1, parainfluenza-3 virus, bovine respiratory syncytial virus, Mannheimia haemolytica and Pasteurella multocida in beef calves, antibody decline by half-life studies and effect on response to vaccination. Vaccine 22:643-649.

Gonda, M. G., Y. M. Chang, G. E. Shook, M. T. Collins, and B. W. Kirkpatrick. 2007. Effect of Mycobacterium paratuberculosis infection on production, reproduction, and health traits in US Holsteins. Prev. Vet. Med. 80:103-119.

Harris, N. B., and R. G. Barletta. 2001. Mycobacterium avium ssp. paratuberculosis in veterinary medicine. Clin. Microbiol. Rev. 4:489-512.

Hutjens, M. F. 2005. Dairy efficiency and dry matter intake. Pages 71-76 in Proc. 7th Western Dairy Management Conf., Reno, NV. Kansas State University Agricultural Experiment Station and Cooperative Extension Service, Manhattan.

Johnson, Y. J., J. B. Kaneene, J. C. Gardiner, J. W. Lloyd, D. J. Sprecher, and P. H. Coe. 2001. The effect of subclinical Mycobacterium paratuberculosis infection on milk production in Michigan dairy cows. J. Dairy Sci. 84:2188-2194.

Körmendy, B., T. Kopál, T. Bálint, M. Szilágyi, and L. Béki. 1989. Economic losses caused by paratuberculosis in a dairy herd: Case report. Acta Vet. Hung. 37:45-53.

Larsen, A. B., R. S. Merkal, and R. C. Cutlip. 1975. Age of cattle as related to resistance to infection with Mycobacterium paratuberculosis. Am. J. Vet. Res. 36:255-257.

Lombard, J. E., F. B. Garry, B. J. McCluskey, and B. A. Wagner. 2005. Risk of removal and effects on milk production associated with paratuberculosis status in dairy cows. J. Am. Vet. Med. Assoc. 227:1975-1981.

McDonald, W. L., S. E. Ridge, A. F. Hope, and R. J. Condron. 1999. Evaluation of diagnostic tests for Johne's disease in young cattle. Aust. Vet. J. 77:113-119.

McNab, W. B., A. H. Meek, S. W. Martin, and J. R. Duncan. 1991. Associations between dairy production indices and lipoarabinomannan enzyme-immunoassay results for paratuberculosis. Can. J. Vet. Res. 55:356-361.

Menanteau-Horta, A. M., T. R. Ames, D. W. Johnson, and J. C. Meiske. 1985. Effect of maternal antibody upon vaccination with infectious bovine rhinotracheitis and bovine virus diarrhea vaccines. Can. J. Comp. Med. 49:10-14.

Mitchell, R. M., R. H. Whitlock, J. M. Smith, M. Wood, N. S. Gollnick, and Y. H. Schukken. 2009. Calf shedding of MAP on two farms with high and low environmental exposure. Proc. 10th Int. Colloq. on Paratuberculosis, Minneapolis, MN. Accessed Novem- 
ber 5, 2010. http://pubs.paratuberculosis.org/index.php/paratb/ article/viewFile/821/420.

Nieuwhof, G. J., H. D. Norman, and F. N. Dickinson. 1989. Phenotypic trends in herdlife of dairy cows in the United States. J. Dairy Sci. 72:726-736.

Nordlund, K. V., W. J. Goodger, J. Pelletier, and M. T. Collins. 1996. Association between subclinical paratuberculosis and milk production, milk components, and somatic cell counts in dairy herds. J. Am. Vet. Med. Assoc. 208:1872-1876.

Raizman, E. A., J. Fetrow, S. J. Wells, S. M. Godden, M. J. Oakes, and G. Vazquez. 2007. The association between Mycobacterium avium subsp. paratuberculosis fecal shedding or clinical Johne's disease and lactation performance on two Minnesota, USA dairy farms. Prev. Vet. Med. 78:179-195.

Rankin, J. D. 1962. The experimental infection of cattle with $M y$ cobacterium johnei IV. Adult cattle maintained in an infectious environment. J. Comp. Pathol. 72:113-117.

Smith, J. W., A. M. Chapa, I. O. Ely, and W. D. Gilson. 2002. Dairy production and management benchmarks. University of Georgia College of Agricultural and Environmental Sciences Cooperative Extension Service, Bulletin 1193. Accessed Dec. 15, 2009. http:// pubsadmin.caes.uga.edu/files/pdf/B\%201193_2.PDF.

Smith, R. L., Y. T. Grohn, A. K. Pradhan, R. H. Whitlock, J. S. Van Kessel, J. M. Smith, D. R. Wolfgang, and Y. H. Schukken. 2009. A longitudinal study on the impact of Johne's disease status on milk production of individual cows. J. Dairy Sci. 92:2653-2661.

Spangler, E., S. Bech-Nielsen, and L. E. Heider. 1992. Diagnostic performance of two serologic tests and fecal culture for subclinical paratuberculosis, and associations with production. Prev. Vet. Med. 13:185-195.

St. Jean, G. 1996. Treatment of clinical paratuberculosis in cattle Vet. Clin. North Am. Food Anim. Pract. 12:417-430.

Stabel, J. R., M. V. Palmer, B. Harris, B. Plattner, J. Hostetter, and S. Robbe-Austerman. 2009. Pathogenesis of Mycobacterium avium ssp. paratuberculosis in neonatal calves after oral or intraperitoneal experimental infection. Vet. Microbiol. 136:306-313.

Streeter, R. N., G. F. Hoffsis, S. Bech-Nielsen, W. P. Shulaw, and D. M. Rings. 1995. Isolation of Mycobacterium paratuberculosis from colostrum and milk of subclinically infected cows. Am. J. Vet. Res. 56:1322-1324.

Sweeney, R. W. 1996. Transmission of paratuberculosis. Vet. Clin. North Am. Food Anim. Pract. 12:305-312.
Sweeney, R. W., R. H. Whitlock, and A. E. Rosenberger. 1992a. Isolation of Mycobacterium paratuberculosis after oral inoculation of uninfected cattle. Am. J. Vet. Res. 53:1312-1314.

Sweeney, R. W., R. H. Whitlock, and A. E. Rosenberger. 1992b. Mycobacterium paratuberculosis isolated from fetuses of infected cows not manifesting signs of the disease. Am. J. Vet. Res. 53:477-480.

Sweeney, R. W., R. H. Whitlock, and A. E. Rosenberger. 1992c. Mycobacterium paratuberculosis cultured from milk and supramammary lymph nodes of infected asymptomatic cows. J. Clin. Microbiol. 30:166-171.

Tsuruta, S., I. Misztal, and T. J. Lawlor. 2005. Changing definition of productive life in US Holsteins: Effect on genetic correlations. J. Dairy Sci. 88:1156-1165.

USDA. 2008. Johne's Disease on U.S. Dairies, 1991-2007. National Animal Health Monitoring System. USDA-APHIS:VS, CEAH, NAHMS, Fort Collins, CO, USA \#N521.0408. Accessed Dec. 15, 2009. http://www.aphis.usda.gov/animal_health/nahms/dairy/ downloads/dairy07/Dairy07_is_Johnes.pdf.

van Roermund, H. J. W., D. Baker, P. T. J. Willemsen, and M. C. M. de Jong. 2007. Horizontal transmission of Mycobacterium avium ssp. paratuberculosis in cattle in an experimental setting: Calves can transmit the infection to other calves. Vet. Microbiol. 122:270-279

Waters, W. R., J. M. Miller, M. V. Palmer, J. R. Stabel, D. E. Jones, K. A. Koistinen, E. M. Steadham, M. J. Hamilton, W. C. Davis, and J. P. Bannantine. 2003. Early induction of humoral and cellular immune responses during experimental Mycobacterium avium ssp. paratuberculosis infection in calves. Infect. Immun. 71:5130-5138.

Whitlock, R. H., and C. Buergelt. 1996. Preclinical and clinical manifestations of paratuberculosis (including pathology). Vet. Clin. North Am. Food Anim. Pract. 12:345-356.

Whitlock, R. H., I. A. Gardiner, B. L. Mangold, J. Smith, R. W. Sweeney, and Y. Schukken. 2006. Johne's disease: Mycobacterium paratuberculosis super-shedders: Detection and contribution to passive shedding (false-positive fecal cultures). Pages 286-288 in Proc. 39th Annu. Conv. Am. Assoc. Bov. Pract. St. Paul, MN.

Wilson, D. J., C. Rossiter, H. R. Han, and P. M. Sears. 1993. Association of Mycobacterium avium paratuberculosis infection with reduced mastitis, but with decreased milk production and increased cull rate in clinically normal dairy cows. Am. J. Vet. Res. $54: 1851-1857$. 